\title{
Antimicrobial-Associated Anaphylaxis \\ Consequences on Infection Related Mortality and Prolonged Hospitalization
}

Laila Carolina Abu Esba ( $\sim$ lailaesba@gmail.com )

King Abdulaziz Medical City

Faisal Aqeel Sehli

King Abdulaziz Medical City

\section{Research Article}

Keywords: Allergy, Antimicrobial, Anaphylaxis, Antimicrobial stewardship

Posted Date: February 24th, 2021

DOl: https://doi.org/10.21203/rs.3.rs-243846/v1

License: (c) (1) This work is licensed under a Creative Commons Attribution 4.0 International License.

Read Full License 


\section{Abstract}

Background: Antimicrobial-associated anaphylaxis occurs at different rates and can lead to worsening infection-related outcomes, we sought to describe the incidence and complications of such episodes at a tertiary care hospital.

Method: A retrospective cohort study was conducted between January 2016 and December 2019. Cases of antimicrobial-associated anaphylaxis were identified using the hospital's electronic healthcare records. Outcomes included: mortality related to anaphylaxis, infection-related mortality, prolonged hospitalization and impact on antimicrobial prescribing.

Results: The estimated rate of antimicrobial-associated anaphylaxis was 18.6 (95\% Cl: 11.8 -29.5) cases per 100,000 exposures. Prolonged hospitalization was seen in $52.4 \%$ of the cases, and major predictors for prolonged hospitalization were a switch to a more toxic antimicrobial (P 0.029) and switch to a broader spectrum antimicrobial (P 0.033).

Conclusion: Implications from antimicrobial-associated anaphylaxis is beyond the episode itself, and can be associated with poor clinical outcomes such as infection-related mortality and prolonged hospitalization.

\section{Introduction:}

Anaphylaxis as defined by the European Academy of Allergy and Clinical Immunology is a severe, lifethreatening, generalized, or systemic hypersensitivity reaction ${ }^{[1]}$. The incidence of anaphylaxis was estimated by the American College of Allergy, Asthma, and Immunology, Epidemiology of Anaphylaxis Working Group to be approximately 50 to 2,000 episodes per 100,000 persons or lifetime prevalence of $0.05-2.0 \%{ }^{[2]}$.

Data from the European Anaphylaxis Registry showed that antimicrobials accounted for $26 \%$ of anaphylaxis cases in elderly patients ${ }^{[3]}$. Recent studies report an increase in the rate of medicationrelated anaphylaxis mortality in different countries $[4,5]$.

Penicillin associated fatal anaphylaxis was described to occur at a rate of $0.002 \%$ among the United States (US) general population and is estimated to account for 400 penicillin- anaphylactic related deaths annually ${ }^{[6]}$.

In a study of 151 anaphylactic related fatalities following penicillin administration, authors reported that $14 \%$ had a history of allergies of some kind, $70 \%$ had received penicillin previously, and one third experienced prior allergic reactions. With the majority of cases leading to death within 15 minutes ${ }^{[7]}$. This highlights the importance of proper allergy history documentation, and also indicates that previous tolerance to penicillin cannot be used as an indicator of safety, as anaphylaxis type reactions are 
prompted by an immunologic response involving immunoglobulin $E$ (IgE) which necessitates a previous exposure.

The consequences of drug-related anaphylaxis have been described in two clinical settings pre-surgical and during pregnancy $[8,9,10]$. In a population-based descriptive study using the United Kingdom Obstetric Surveillance System, the complications of anaphylaxis during pregnancy was assessed, results showed that out of the cases included, antibiotics were the main culprit, $(5 \%)$ of women died, (38\%) required intensive care admission and (19\%) had one or more additional severe maternal morbidities. There were no infant mortalities; however, in those infants whose mother had anaphylaxis before delivery $(41 \%)$ required neonatal intensive care unit admissions ${ }^{[8]}$.

In the pre-surgical setting, the event of anaphylaxis can be more problematic due to the complex setting and multiple medications that are initiated simultaneously, it is often difficult to identify the true culprit. It was commonly thought that muscle relaxants were the main offenders in this setting, however in a study that identified cases of anaphylaxis during surgery that occurred over a period of 11 years at a tertiary hospital in the US; anaphylaxis was more commonly elicited by antibiotics ${ }^{[9]}$. Similar results were reported from a large study in the UK, where the most common causes of perioperative anaphylaxis were antibiotics ${ }^{[10]}$.

In Saudi Arabia a cross-sectional study of medical records reported a period prevalence of anaphylaxis among emergency department (ED) admissions of $0.00026 \%$ out of $617,401 \mathrm{ED}$ admissions; of which only $17.4 \%$ were triggered by drugs; with the majority being antibiotics ${ }^{[11]}$. Besides this study, our literature search revealed only another study in Saudi Arabia that described the demographics of patients being prescribed adrenaline auto-injectors for anaphylaxis ${ }^{[12]}$.

There are likely geographical differences in the incidence of antimicrobial-related anaphylaxis, mainly due to differences in antimicrobial selection, preferences, epidemiology of infections, and local resistance patterns; therefore, there is a need to better understand this risk on both a country and institutional level.

The landscape of anaphylaxis associated specifically with antimicrobials is not well described, particularly in an in-patient setting. Therefore, the objective of our study was to describe the incidence and undesirable outcomes of antimicrobial-associated anaphylaxis.

\section{Methods:}

2.1 Study Design \& Setting: A retrospective cohort study was conducted between January 2016 and December 2019 at a tertiary care hospital with a bed capacity of 2,100 beds. Cases of antimicrobialassociated anaphylaxis were identified using the hospital's electronic healthcare records (EHRs), which documents patient's drug allergies under a specific field. The search terms used included anaphylaxis and anaphylactic shock. Cases identified then underwent further chart review assessment based on our inclusion and exclusion criteria (see below). 
All patient's medical records were reviewed to ensure that antimicrobials were the suspected culprit in the documented anaphylaxis.

\subsection{Inclusion Criteria}

Inclusion criteria: adult and pediatric patients, with antimicrobial-associated anaphylaxis documented or reported during hospitalization, with a clear description of signs and symptoms documented in patient's chart; that met one of the three following description (based on National Institute of Health 2006 definition) ${ }^{[13]}$

1. Acute onset (within minutes to hours of exposure) of a skin or mucosal involvement with at least one of the following: respiratory compromise and/or reduced blood pressure with associated targetorgan dysfunction

2. Two or more of the following occurring rapidly (minutes to hours of exposure) after exposure of a likely allergen: skin or mucosal tissue involvement, respiratory compromise, decreased blood pressure with associated target organ dysfunction, or tenacious gastrointestinal symptoms.

3. Reduced blood pressure occurs after exposure (for infants and children, decreased age-specific systolic blood pressure or a greater than $30 \%$ decrease from baseline; for adults, systolic blood pressure of less than $90 \mathrm{~mm} \mathrm{Hg}$ or greater than a $30 \%$ decrease from baseline.)

\subsection{Exclusion criteria:}

Patients with cutaneous-only reactions, delayed cutaneous reactions, anaphylaxis cases that occurred outside the hospital, and anaphylaxis documented in the old health information system (due to lack of electronic documentation of the event).

Patients with antimicrobial anaphylaxis meeting inclusion criteria had their demographics collected which included: age, gender, route of antimicrobial used, history of asthma/atopic dermatitis, history of other allergies (food or drugs), underwent a desensitization protocol, use of beta-blockers, angiotensinconverting enzyme inhibitors or angiotensin II receptor blockers (ACEls/ARBs).

\subsection{Outcomes}

We intend to determine the rate of anaphylaxis, and the most commonly implicated antimicrobials/classes. While describing the demographics and potential risk factors of patients.

To assess the impact of the antimicrobial-associated anaphylaxis we assessed:

- Mortality related to anaphylaxis

- The infection-related mortality in patients with a reported anaphylaxis

- Prolonged hospitalization (defined as one or more days than anticipated based on the type of infection, and assessed by two independent expert clinical pharmacists) 
To assess the impact on antimicrobial prescribing we assessed the following:

- Percentage of patients that switched to a less effective antimicrobial for the infection being treated

- Percentage of patients that switched to a more toxic antimicrobial

- Percentage of patients that switched to a broader spectrum antimicrobial

The switch to a less effective antimicrobial was defined as switching from a first line to a second line antimicrobial as per our institution's antimicrobial guidelines. A switch to a more toxic antimicrobial was based on two independent clinical pharmacists' reviews and were individualized to each patient based on the overall morbidities and the type of infection (e.g. switching to a nephrotoxic agent in a patient with underlying renal impairment), disputes were further discussed until agreement was reached between the reviewers.

The antimicrobial spectrum of activity was deemed broader based on the spectrum of activity tables in Sanford antimicrobial therapy guide (digital content updated December 29, 2019) ${ }^{[14]}$.

\subsection{Statistical analysis}

Basic statistical analysis via SAS (Institute Inc. Cary, NC, USA), was performed with biostatistician support. We used mean and standard deviation (SD) to summarize the continuous variables and frequency, and percentage to summarize the categorical variables. We used the t-test to compare the average age among the patients that had a prolonged hospitalization to those who are not. A Chi-square test was used to compare the categorical variables across the groups. Fisher exact test was used when the Chi-square test is invalid due to lower expected cross-tabulation cell frequencies. All analyses were conducted using the SAS software package 9.4 (SAS Institute, Cary, NC).

Bivariate analysis for infection related mortality: Fisher exact test was used to compare the infection related mortality and other covariates due to lower expected cross tabulation cell frequencies. Binary logistic regression with firth correction is used to estimate the odds ratio. The estimate of area under the curve of the fitted model is $77.3 \%$.

Binary logistic regression with maximum likelihood estimation was used to estimate the odds ratio of prolonged hospitalization. The estimate of area under the curve of the fitted model is $80.7 \%$.

The institutional review board (IRB) at King Abdullah International Medical Research Center (KAIMRC) (Protocol RC19/339/R) approved this study, and is performed in accordance with the Declaration of Helsinki. No consent form was required by the Ministry of National Guard Health Affairs ethics committee.

\section{Results:}


Between Jan 2016 and Dec. 2019, the total number of documented antimicrobial allergies in the EMRs was 3,656 of which 117 (3.2\%) were antimicrobial induced anaphylaxis; of these, 42 patients that had a documented antimicrobial induced anaphylaxis met the inclusion criteria and the case definition, notably $54(46 \%)$ of the cases were patient self-reported and were therefore excluded. See Fig. 1 for patient selection.

\subsection{Demographics}

Of the 42 cases that were included, $(22 / 42,52 \%)$ were female and the median age was $51 \pm 25.4$ years of which only $(6 / 42,14 \%)$ were pediatric patients. History of asthma was recorded in eleven participants $(11 / 42,26.19 \%)$. History of other allergies was recorded in 15 patients $(15 / 42,35.7 \%)$, which included mainly other drugs and food allergies. Thirteen (13/42, 30.9\%) patients were on a beta-blocker, and eight (8/42, 19\%) were on an ACEl/ARB. See Table 1 for demographics. 
Table 1

Demographics and outcomes in patients with antimicrobial-induced anaphylaxis and Bivariate Analysis for Prolonged Hospitalization

\begin{tabular}{|c|c|c|c|c|c|}
\hline \multirow[t]{2}{*}{ Variable Name } & \multirow[t]{2}{*}{ Level } & \multirow[t]{2}{*}{$n=42$} & \multicolumn{2}{|c|}{ Prolonged hospitalization } & \multirow{2}{*}{$\begin{array}{l}P \\
\text { value }\end{array}$} \\
\hline & & & No $(n=20)$ & $\begin{array}{l}\text { Yes }(n= \\
22)\end{array}$ & \\
\hline \multirow[t]{3}{*}{ Age, median (Q1 - Q3), years } & & 49 & 46 & 62 & \multirow[t]{3}{*}{0.208} \\
\hline & & $(31-76)$ & $(25.5-57.5)$ & $(39-79)$ & \\
\hline & & $\begin{array}{l}\text { Frequency } \\
(\%)\end{array}$ & Frequency (\%) & $\begin{array}{l}\text { Frequency } \\
(\%)\end{array}$ & \\
\hline \multicolumn{6}{|l|}{ Age } \\
\hline & $\begin{array}{l}\text { Less than } 65 \\
\text { years }\end{array}$ & $\begin{array}{l}29 \\
(69.05 \%)\end{array}$ & $16(55.17 \%)$ & $\begin{array}{l}13 \\
(44.83 \%)\end{array}$ & \multirow[t]{2}{*}{0.143} \\
\hline & $\begin{array}{l}65 \text { years or } \\
\text { more }\end{array}$ & $\begin{array}{l}13 \\
(30.95 \%)\end{array}$ & $4(30.77 \%)$ & $\begin{array}{l}9 \\
(69.23 \%)\end{array}$ & \\
\hline \multicolumn{6}{|l|}{ Gender } \\
\hline & Female & $\begin{array}{l}22 \\
(52.38 \%)\end{array}$ & $13(59.09 \%)$ & $\begin{array}{l}9 \\
(40.91 \%)\end{array}$ & \multirow[t]{2}{*}{0.119} \\
\hline & Male & $\begin{array}{l}20 \\
(47.62 \%)\end{array}$ & 7 (35\%) & $13(65 \%)$ & \\
\hline \multicolumn{6}{|l|}{$\begin{array}{l}\text { Death related to the } \\
\text { anaphylactic event }\end{array}$} \\
\hline & No & $\begin{array}{l}41 \\
(97.62 \%)\end{array}$ & $19(46.34 \%)$ & $\begin{array}{l}22 \\
(53.66 \%)\end{array}$ & \multirow[t]{2}{*}{$0.476^{\star}$} \\
\hline & Yes & $1(2.38 \%)$ & $1(100 \%)$ & $0(0 \%)$ & \\
\hline \multicolumn{6}{|l|}{ Infection-Related Mortality } \\
\hline & No & $\begin{array}{l}37 \\
(88.1 \%)\end{array}$ & $18(48.65 \%)$ & $\begin{array}{l}19 \\
(51.35 \%)\end{array}$ & \multirow[t]{2}{*}{$1 *$} \\
\hline & Yes & $5(11.9 \%)$ & $2(40 \%)$ & $3(60 \%)$ & \\
\hline \multicolumn{6}{|l|}{ Cardiac Arrest } \\
\hline & No & $\begin{array}{l}37 \\
(88.1 \%)\end{array}$ & $18(48.65 \%)$ & $\begin{array}{l}19 \\
(51.35 \%)\end{array}$ & \multirow[t]{2}{*}{$1 *$} \\
\hline & Yes & $5(11.9 \%)$ & $2(40 \%)$ & $3(60 \%)$ & \\
\hline
\end{tabular}




\begin{tabular}{|c|c|c|c|c|c|}
\hline \multirow[t]{2}{*}{ Variable Name } & \multirow[t]{2}{*}{ Level } & \multirow[t]{2}{*}{$n=42$} & \multicolumn{2}{|c|}{ Prolonged hospitalization } & \multirow{2}{*}{$\begin{array}{l}\mathrm{P} \\
\text { value }\end{array}$} \\
\hline & & & No $(n=20)$ & $\begin{array}{l}\text { Yes }(n= \\
22)\end{array}$ & \\
\hline & No & $\begin{array}{l}28 \\
(66.67 \%)\end{array}$ & $15(53.57 \%)$ & $\begin{array}{l}13 \\
(46.43 \%)\end{array}$ & \multirow[t]{2}{*}{0.245} \\
\hline & Yes & $\begin{array}{l}14 \\
(33.33 \%)\end{array}$ & $5(35.71 \%)$ & $\begin{array}{l}9 \\
(64.29 \%)\end{array}$ & \\
\hline \multicolumn{6}{|c|}{$\begin{array}{l}\text { Switch to less effective } \\
\text { antimicrobial }\end{array}$} \\
\hline & No & $\begin{array}{l}31 \\
(73.81 \%)\end{array}$ & $17(54.84 \%)$ & $\begin{array}{l}14 \\
(45.16 \%)\end{array}$ & \multirow[t]{2}{*}{0.116} \\
\hline & Yes & $\begin{array}{l}11 \\
(26.19 \%)\end{array}$ & $3(27.27 \%)$ & $\begin{array}{l}8 \\
(72.73 \%)\end{array}$ & \\
\hline \multicolumn{6}{|c|}{$\begin{array}{l}\text { Switch to a more toxic } \\
\text { antimicrobial }\end{array}$} \\
\hline & No & $\begin{array}{l}22 \\
(52.38 \%)\end{array}$ & $14(63.64 \%)$ & $\begin{array}{l}8 \\
(36.36 \%)\end{array}$ & \multirow[t]{2}{*}{0.029} \\
\hline & Yes & $\begin{array}{l}20 \\
(47.62 \%)\end{array}$ & $6(30 \%)$ & $14(70 \%)$ & \\
\hline \multicolumn{6}{|c|}{$\begin{array}{l}\text { Switch to a broader spectrum } \\
\text { antimicrobial }\end{array}$} \\
\hline & No & $\begin{array}{l}29 \\
(69.05 \%)\end{array}$ & $17(58.62 \%)$ & $\begin{array}{l}12 \\
(41.38 \%)\end{array}$ & \multirow[t]{2}{*}{0.033} \\
\hline & Yes & $\begin{array}{l}13 \\
(30.95 \%)\end{array}$ & $3(23.08 \%)$ & $\begin{array}{l}10 \\
(76.92 \%)\end{array}$ & \\
\hline \multicolumn{6}{|c|}{ Underwent a desensitization } \\
\hline & No & $42(100 \%)$ & $20(47.62 \%)$ & $\begin{array}{l}22 \\
(52.38 \%)\end{array}$ & \\
\hline \multicolumn{6}{|l|}{ Asthma } \\
\hline & No & $\begin{array}{l}31 \\
(73.81 \%)\end{array}$ & $16(51.61 \%)$ & $\begin{array}{l}15 \\
(48.39 \%)\end{array}$ & \multirow[t]{2}{*}{0.384} \\
\hline & Yes & $\begin{array}{l}11 \\
(26.19 \%)\end{array}$ & $4(36.36 \%)$ & $\begin{array}{l}7 \\
(63.64 \%)\end{array}$ & \\
\hline \multicolumn{6}{|l|}{ Atopic dermatitis } \\
\hline & No & $42(100 \%)$ & $20(47.62 \%)$ & $\begin{array}{l}22 \\
(52.38 \%)\end{array}$ & \\
\hline
\end{tabular}

*Fisher exact test is used 


\begin{tabular}{|c|c|c|c|c|c|}
\hline \multirow[t]{2}{*}{ Variable Name } & \multirow[t]{2}{*}{ Level } & \multirow[t]{2}{*}{$n=42$} & \multicolumn{2}{|c|}{ Prolonged hospitalization } & \multirow{2}{*}{$\begin{array}{l}P \\
\text { value }\end{array}$} \\
\hline & & & No $(n=20)$ & $\begin{array}{l}\text { Yes }(n= \\
22)\end{array}$ & \\
\hline \multicolumn{6}{|l|}{ Other allergies } \\
\hline & No & $\begin{array}{l}27 \\
(64.29 \%)\end{array}$ & $15(55.56 \%)$ & $\begin{array}{l}12 \\
(44.44 \%)\end{array}$ & \multirow[t]{2}{*}{0.167} \\
\hline & Yes & $\begin{array}{l}15 \\
(35.71 \%)\end{array}$ & $5(33.33 \%)$ & $\begin{array}{l}10 \\
(66.67 \%)\end{array}$ & \\
\hline \multicolumn{6}{|l|}{ Beta-blockers } \\
\hline & No & $\begin{array}{l}29 \\
(69.05 \%)\end{array}$ & $14(48.28 \%)$ & $\begin{array}{l}15 \\
(51.72 \%)\end{array}$ & \multirow[t]{2}{*}{0.899} \\
\hline & Yes & $\begin{array}{l}13 \\
(30.95 \%)\end{array}$ & $6(46.15 \%)$ & $\begin{array}{l}7 \\
(53.58 \%)\end{array}$ & \\
\hline \multicolumn{6}{|l|}{ ACEI/ARB } \\
\hline & No & $\begin{array}{l}34 \\
(80.95 \%)\end{array}$ & $18(52.94 \%)$ & $\begin{array}{l}16 \\
(47.06 \%)\end{array}$ & \multirow[t]{2}{*}{0.155} \\
\hline & Yes & $\begin{array}{l}8 \\
(19.05 \%)\end{array}$ & $2(25.00 \%)$ & $\begin{array}{l}6 \\
(75.00 \%)\end{array}$ & \\
\hline \multicolumn{6}{|c|}{$\begin{array}{l}\text { Concomitant drugs during } \\
\text { anaphylaxis }\end{array}$} \\
\hline & No & $\begin{array}{l}39 \\
(92.86 \%)\end{array}$ & $20(51.28 \%)$ & $\begin{array}{l}19 \\
(48.72 \%)\end{array}$ & \multirow[t]{2}{*}{$0.233^{*}$} \\
\hline & Yes & $3(7.14 \%)$ & $0(0 \%)$ & $3(100 \%)$ & \\
\hline
\end{tabular}

\subsection{Rate of Antimicrobial Anaphylaxis}

In an estimated 100,000 antimicrobial prescriptions during the period of the study, the estimated rate of antimicrobial-associated anaphylaxis was 18.6 (95\% Cl: 11.8 -29.5) cases per 100,000 exposures.

\subsection{Frequency of implicated antimicrobials}

Figure 2 shows the frequency of antimicrobials implicated in antimicrobial anaphylaxis and the number of anaphylaxis episodes according to each antimicrobial class. Overall, ceftriaxone induced anaphylaxis was the most frequently implicated antimicrobial (10/42 episodes, $23.8 \%$ ). The estimated incidence for ceftriaxone was 48.9 (95\% Cl: 19.0 - 125.6) cases per 100,000 exposures.

\subsection{Prolonged Hospitalization}


The prevalence of prolonged hospitalization as a result of the anaphylaxis was $52.38 \%$ (95\% Cl: 37.32 66.64). Five patients suffered a cardiac arrest $(5 / 42,11.9 \%)$ and a code blue was activated in 14 cases $(14 / 42,33.3 \%)$.

The major predictors for prolonged hospitalization per antimicrobial anaphylaxis episode were found to be associated with a switch to a more toxic antimicrobial ( $P$ 0.029) and switch to a broader spectrum antimicrobial (P 0.033). See Table 1 and 2.

Table 2

Odds Ratio for Prolonged Hospitalization*

\begin{tabular}{|lll|}
\hline Effect & OR (95\% Confidence Limits) & P-Value \\
\hline Age - 65 years or more & $2.208(0.393-12.398)$ & 0.3682 \\
\hline Gender - Male & $3.628(0.713-18.472)$ & 0.1206 \\
\hline Switch to less effective antimicrobial - Yes & $2.113(0.361-12.352)$ & 0.4064 \\
\hline Switch to more toxic antimicrobial - Yes & $1.831(0.246-13.638)$ & 0.5551 \\
\hline Switch to broad spectrum antimicrobial - Yes & $4.015(0.416-38.717)$ & 0.2293 \\
\hline Asthma - Yes & $1.233(0.22-6.904)$ & 0.8113 \\
\hline Other allergies - Yes & $1.702(0.354-8.175)$ & 0.5068 \\
\hline *Binary logistic regression with maximum likelihood estimation is used to estimate the odds ratio. \\
\hline
\end{tabular}

\subsection{Therapeutic Changes}

In eleven of the cases patients were switched to a less effective antimicrobial (11/42, 26.19\%), 20 switched to a more toxic antimicrobial $(20 / 42,47.62 \%)$, and $(13 / 42,30.9 \%)$ patients switched to a broader spectrum antimicrobial. In $(11 / 42,26.2 \%)$ patients no antimicrobial was prescribed after the anaphylaxis episode (excluding two patients who died shortly after the anaphylaxis episode before switching to another antimicrobial). None of the patients underwent a desensitization attempt.

\subsection{Mortality Associated with Antimicrobial Anaphylaxis Episodes}

The outcomes in patients with antimicrobial associated anaphylaxis are shown in Table 1. There was only one mortality $1(1 / 42,2.38 \%)$ related directly to an anaphylaxis event which involved amphotericin $B$, this patient did not have a history of asthma or atopy, no history of other allergies, he was on a betablocker, and was immunocompromised. There were five infection-related mortalities (5/42, $11.9 \%)$, of which 3 were switched to a more toxic antimicrobial, and the other 2 cases died shortly after the episode and were not switched to any other antimicrobial in between the time of the anaphylaxis episode and 
death. None of the predictors for infection-related mortalities were significant besides code-blue activation (P 0.035). See Table 3 and 4. 
Table 3

Bivariate Analysis for Infection Related Mortality*

\begin{tabular}{|c|c|c|c|c|}
\hline \multirow[t]{2}{*}{ Variable name } & \multirow[t]{2}{*}{ Level } & \multicolumn{2}{|c|}{ Infection related mortality } & \multirow{2}{*}{$\begin{array}{l}P \\
\text { value }\end{array}$} \\
\hline & & No $(n=37)$ & Yes $(n=5)$ & \\
\hline \multirow[t]{2}{*}{ Age, median (Q1 - Q3), years } & & $49(26-75)$ & $62(46-79)$ & 0.172 \\
\hline & & $\begin{array}{l}\text { Frequency } \\
(\%)\end{array}$ & $\begin{array}{l}\text { Frequency } \\
(\%)\end{array}$ & \\
\hline \multicolumn{5}{|l|}{ Age } \\
\hline & $\begin{array}{l}\text { Less than } 65 \\
\text { years }\end{array}$ & $26(89.66 \%)$ & $3(10.34 \%)$ & \multirow[t]{2}{*}{0.637} \\
\hline & 65 years or more & $11(84.62 \%)$ & $2(15.38 \%)$ & \\
\hline \multicolumn{5}{|l|}{ Gender } \\
\hline & Female & $20(90.91 \%)$ & $2(9.09 \%)$ & \multirow[t]{2}{*}{0.656} \\
\hline & Male & $17(85 \%)$ & $3(15 \%)$ & \\
\hline \multicolumn{5}{|l|}{ Cardiac arrest } \\
\hline & No & $34(91.89 \%)$ & $3(8.11 \%)$ & \multirow[t]{2}{*}{0.099} \\
\hline & Yes & $3(60 \%)$ & $2(40 \%)$ & \\
\hline \multicolumn{5}{|l|}{ Code blue activated } \\
\hline & No & $27(96.43 \%)$ & $1(3.57 \%)$ & \multirow[t]{2}{*}{0.035} \\
\hline & Yes & $10(71.43 \%)$ & $4(28.57 \%)$ & \\
\hline \multicolumn{5}{|c|}{ Switch to less effective antimicrobial } \\
\hline & No & $27(87.1 \%)$ & $4(12.9 \%)$ & \multirow[t]{2}{*}{1} \\
\hline & Yes & $10(90.91 \%)$ & $1(9.09 \%)$ & \\
\hline \multicolumn{5}{|c|}{ Switch to more toxic antimicrobial } \\
\hline & No & $20(90.91 \%)$ & $2(9.09 \%)$ & \multirow[t]{2}{*}{0.656} \\
\hline & Yes & $17(85 \%)$ & $3(15 \%)$ & \\
\hline \multicolumn{5}{|l|}{$\begin{array}{l}\text { Switch to broad spectrum } \\
\text { antimicrobial }\end{array}$} \\
\hline & No & 25 (86.21\%) & $4(13.79 \%)$ & \multirow[t]{2}{*}{1} \\
\hline & Yes & 12 (92.31\%) & 1 (7.69\%) & \\
\hline
\end{tabular}

*Fisher exact test is used to compare the infection related mortality and other covariates due to lower expected cross tabulation cell frequencies. 


\begin{tabular}{|c|c|c|c|c|}
\hline \multirow[t]{2}{*}{ Variable name } & \multirow[t]{2}{*}{ Level } & \multicolumn{2}{|c|}{ Infection related mortality } & \multirow{2}{*}{$\begin{array}{l}P \\
\text { value }\end{array}$} \\
\hline & & No $(n=37)$ & Yes $(n=5)$ & \\
\hline \multicolumn{5}{|c|}{ Underwent desensitization } \\
\hline & No & 37 (88.1\%) & $5(11.9 \%)$ & \\
\hline \multicolumn{5}{|l|}{ Asthma } \\
\hline & No & $26(83.87 \%)$ & $5(16.13 \%)$ & \multirow[t]{2}{*}{0.303} \\
\hline & Yes & $11(100 \%)$ & $0(0 \%)$ & \\
\hline \multicolumn{5}{|l|}{ Atopic dermatitis } \\
\hline & No & $37(88.1 \%)$ & $5(11.9 \%)$ & \\
\hline \multicolumn{5}{|l|}{ Other allergies } \\
\hline & No & $23(85.19 \%)$ & $4(14.81 \%)$ & \multirow[t]{2}{*}{0.639} \\
\hline & Yes & $14(93.33 \%)$ & $1(6.67 \%)$ & \\
\hline \multicolumn{5}{|l|}{ Beta-blockers } \\
\hline & No & $27(93.1 \%)$ & $2(6.9 \%)$ & \multirow[t]{2}{*}{0.162} \\
\hline & Yes & 10 (76.92\%) & 3 (23.08\%) & \\
\hline \multicolumn{5}{|c|}{ ACE/ARB inhibitors } \\
\hline & No & $30(88.24 \%)$ & $4(11.76 \%)$ & \multirow[t]{2}{*}{1} \\
\hline & Yes & $7(87.5 \%)$ & $1(12.5 \%)$ & \\
\hline
\end{tabular}


Table 4

Odds ratio for Infection Related Mortality*

\begin{tabular}{|lll|}
\hline Effect & OR (95\% Confidence Limits) & P Value \\
\hline Age - 65 years or more & $2.683(0.3-23.966)$ & 0.3769 \\
\hline Gender - Male & $1.404(0.209-9.447)$ & 0.727 \\
\hline Switch to less effective antimicrobial - Yes & $0.525(0.044-6.247)$ & 0.6098 \\
\hline Switch to more toxic antimicrobial - Yes & $4.214(0.457-38.828)$ & 0.2043 \\
\hline Switch to broad spectrum antimicrobial - Yes & $0.213(0.015-2.96)$ & 0.2494 \\
\hline Asthma - Yes & $0.198(0.012-3.152)$ & 0.2512 \\
\hline $\begin{array}{l}\text { Other allergies - Yes } \\
\text { *Binary logistic regression with firth correction is used to estimate the odds ratio. The estimate of area } \\
\text { under the curve of the fitted model is 77.3\%. }\end{array}$ & 0.8295 \\
\hline
\end{tabular}

\section{Discussion:}

The rate of antimicrobial associated anaphylaxis in the two large healthcare facilities included in this study was 18.6 (95\% Cl: 11.8 - 29.5) cases per 100000 exposures. Compared to a large national study from the UK which reported an overall incidence of reported antibiotic-induced anaphylaxis was 4.0 per 100000 exposures, where the highest incidence was seen with teicoplanin (16.4 per 100000 exposures) then co-amoxiclav (8.7 per 100000 exposures), our incident seems higher and involves different antibiotics ${ }^{[10]}$.

In a US population-based study utilizing EHRs of patients with active healthcare plans over a period of 9 years, out of 7,449,076 patients assessed; they found only 1 of $1543(0.065 \%)$ oral and 1 of 1030 $(0.097 \%)$ parenteral confirmed penicillin-associated anaphylaxis ${ }^{[15]}$. Although different in design, compared to our study this incidence seems much less than that reported in our study.

Epidemiological data from different countries have reported a drug anaphylaxis fatality rate of between 0.05-0.51 per million/year, with antimicrobials being the leading causal drug ${ }^{[16]}$. In our study period, there was one drug anaphylaxis related mortality; this is in line with reports from other countries where fatalities in hospitalized anaphylaxis cases are very uncommon $[17,18,19]$.

Low mortality rates could be explained by the easily identifiable anaphylaxis symptoms, which are rapid in onset and classic. In addition to the availability of anaphylactic kits in almost all areas within the hospital and familiarity of staff in managing anaphylaxis events.

Interestingly the majority of antimicrobial anaphylaxis documented in the EHRs which were excluded from our study, were patient self-reported. This may have implications on antimicrobial choices and 
infection outcomes; as the accuracy of patient-reported antimicrobial allergy history has been brought to question ${ }^{[20]}$. This finding raises the need for better tools to identify, document, and classify patient's allergies, in order to facilitate the decision process should the patient have a forthcoming need for an antimicrobial. De-labeling patients that may not be truly allergic to antimicrobials has been of interest lately, with successful experiences reported ${ }^{[21,22]}$.

Our study is the first in the region to explore the epidemiology and outcomes of antimicrobial anaphylaxis. A key finding was that unlike other studies where penicillins/aminopenicillins have been reported to be the most frequently implicated antimicrobial class in antimicrobial anaphylaxis; in our setting cephalosporins were the top implicated antimicrobials, driven mainly by anaphylaxis associated with ceftriaxone.

The International Collaborative Study of Severe Anaphylaxis reports an incidence of parenteral cephalosporin-associated anaphylaxis of 5.7 cases per 100000 exposures ${ }^{[23]}$. While the real-world frequency of anaphylaxis from 12 California hospitals reports a lower incidence of 0.6 cases per 100000 exposures with oral cephalosporins and 1.6 per 100000 exposures with parenteral cephalosporin [24].

The rate of ceftriaxone-induced anaphylaxis was higher in our study 48.9 (95\% Cl: 19.0 - 125.6) cases per 100000 exposures. Such high incidence has been reported in a Korean study of 76 cephalosporin-induced anaphylaxis where the highest incidence was reported with ceftriaxone (9.2 per 100000 exposures) [25], this difference in incidence may suggest a genetic predisposition to this reaction to ceftriaxone in these two populations.

Ceftriaxone is a third-generation parenteral cephalosporin and an essential antibiotic that is listed as a first-line agent for multiple susceptible organisms including N. gonorrhea, N. meningitides, and H.influenzae ${ }^{[26]}$. It is generally considered well tolerated with no dose adjustments required in patients with renal or hepatic impairment. Therefore, besides the high incidence of ceftriaxone anaphylaxis and implications of managing an episode, poor infection-related outcomes should be expected in cases where ceftriaxone were to be replaced by a second line agent.

In our study in $26.2 \%$ of the cases, the patient's antimicrobial was discontinued after the anaphylaxis event with no further orders for any other antimicrobial; out of which, the majority were initiated empirically, and none were associated with mortality. Although assessing antimicrobial appropriateness was out of the scope of this study, it is startling to say that in almost a quarter of the cases antimicrobials may have been prescribed unnecessarily.

A switch to a more toxic antimicrobial, and/or a broader spectrum antimicrobial were predictors of prolonged hospitalization in our study. As a severe allergic reaction drives prescribers away from their first empiric choice this outcome is foreseen and expected. Prolonged hospitalization has both morbidity and economic consequences and was significantly high in the population studied here $>50 \%$. However, 
interpretation should be made cautiously since we did not control confounders such as disease severity due to the small sample size.

In the five infection-related mortality cases, one patient's culture grew carbapenem-resistant Klebsiella pneumoniae with the OXA48 gene detected while the other four patient's cultures did not grow any resistant organisms. Possibly indicating that mortality was driven by adverse drug toxicity rather than a drug-bug mismatch.

In none of the cases was desensitization attempted, although desensitization is an effective approach to patients with a clear IgE type reaction. There are multiple published desensitization protocols $[27,28,29]$, prescribers may need to more frequently weigh the benefit of a desensitization approach vs switching to a less favorable antimicrobial.

\section{Study Limitations:}

Case definition: we only included patients that had explicitly an anaphylaxis episode recorded in their files, this could have excluded other cases where the symptoms of anaphylaxis were documented such as hypotension, shortness of breath, and/or collapse but the term anaphylaxis was not explicitly used. The prolonged hospital stay was subjectively assessed by the authors.

\section{Conclusion:}

Implications of antimicrobial-associated anaphylaxis are beyond the episode itself, and can be associated with poor clinical outcomes such as infection-related mortality and prolonged hospitalization, further research into measures to predict and manage antimicrobial anaphylaxis could sever antimicrobial stewardship programs.

Authors certify that there were no funding sources to complete this project, and have no conflict of interests

\section{Abbreviations:}

ACEls/ARBs: angiotensin converting enzyme inhibitors or angiotensin II receptor blockers

ADR: Adverse Drug Reaction

ED: emergency department

EHRs: electronic healthcare records

$\lg \mathrm{E}:$ immunoglobulin $\mathrm{E}$

US: United States 


\section{References:}

1. Johansson, S.G.O., Hourihane, J., Bousquet, J., Bruijnzeel-Koomen, C., Dreborg, S., Haahtela, T., Kowalski, M.L., Mygind, N., Ring, J., Van Cauwenberge, P., Van Hage-Hamsten, M. and Wüthrich, B. (2001), A revised nomenclature for allergy: An EAACl position statement from the EAACl nomenclature task force. Allergy, 56: 813-824. doi:10.1111/j.1398-9995.2001.00002.x-i1

2. P. Lieberman, Camargo C. a, K. Bohlke, et al. Epidemiology of anaphylaxis: findings of the american college of allergy, asthma and immunology epidemiology of anaphylaxis working group. Ann Allergy Asthma Immunol [Internet], 97 (5) (2006), pp. 596-602.

3. Aurich S, Dölle-Bierke S, Francuzik W, et al. Anaphylaxis in Elderly Patients-Data From the European Anaphylaxis Registry. Front Immunol. 2019;10:750. Published 2019 Apr 24. doi:10.3389/fimmu.2019.00750

4. Chaaban MR, Warren Z, Baillargeon JG et al. Epidemiology and trends of anaphylaxis in the United States, 2004-2016. Int Forum Allergy Rhinol 2019; 9: 607-14

5. Mullins RJ, Wainstein BK, Barnes EH et al. Increases in anaphylaxis fatalities in Australia from 1997 to 2013. Clin Exp Allergy 2016; 46: 1099-110

6. Neugut Al, Ghatak AT, Miller RL. Anaphylaxis in the United States: An Investigation Into Its Epidemiology. Arch Intern Med. 2001;161(1):15-21. doi:10.1001/archinte.161.1.15

7. Idsoe 0 , Guthe T, Willcox R, De Weck A. Nature and extent of penicillin side-reactions, with particular reference to anaphylactic shock. Bull World Health Organ 1968;38: 159-88

8. McCall, SJ, Bunch, KJ, Brocklehurst, P, D'Arcy, R, Hinshaw, K, Kurinczuk, JJ, Lucas, DN, Stenson, $B$, Tuffnell, DJ, Knight, M. The incidence, characteristics, management and outcomes of anaphylaxis in pregnancy: a population-based descriptive study. BJOG 2018; 125: 965- 971.

9. Gurrieri C. Allergic reactions during anesthesia at a large United States referral center. Anesth Analg. 2011;113:1202-212.doi:10.1213/ANE.0b013e31822d45ac

10. Harper NJN, Cook TM, Garcez T, Farmer L, Floss K, Marinho S, et al. Anesthesia, surgery, and life threatening allergic reaction: epidemiology and clinical features of perioperative anaphylaxis in the 6th National Audit Project (NAP6). Br J Anaesth. (2018) 121:159-171. 10.1016/j.bja.2018.04.014

11. Alkanhal R, Alhoshan I, Aldakhil S, et al. Prevalence triggers and clinical severity associated with anaphylaxis at a tertiary care facility in Saudi Arabia: A cross-sectional study. Medicine (Baltimore). 2018;97(31):e11582. doi:10.1097/MD.0000000000011582

12. Sheikh, Farrukh et al. "First study of pattern of anaphylaxis in a large tertiary care hospital in Saudi Arabia." Asia Pacific allergy vol. 5,4 (2015): 216-21. doi:10.5415/apallergy.2015.5.4.216

13. Sampson HA, Munoz-Furlong A, Campbell RI, et al. Second symposium on the definition and management of anaphylaxis: Summary report - second National Institutes of Allergy and Infectious Disease/Food Allergy and Anaphylaxis network symposium. JACI 2006; 117:391-7.

14. The Sanford Guide, Antimicrobial Therapy, Inc. Digital content updated December 29, 2019 
15. Emily H. Liang, Lie H. Chen, Eric Macy. Adverse Reactions Associated with Penicillins, Carbapenems, Monobactams, and Clindamycin: A Retrospective Population-based Study. J Allergy Clin Immunol Pract. 2019 Dec 9. pii: S2213-2198(19)31017-7. doi: 10.1016/j.jaip.2019.11.035

16. Turner PJ, Jerschow E, Umasunthar T, Lin R, Campbell DE, Boyle RJ. Fatal Anaphylaxis: Mortality Rate and Risk Factors. J Allergy Clin Immunol Pract. 2017;5(5):1169-1178. doi:10.1016/j.jaip.2017.06.031

17. Turner P.J., Gowland M.H., Sharma V., lerodiakonou D., Harper N., Garcez T. Increase in anaphylaxisrelated hospitalizations but no increase in fatalities: an analysis of United Kingdom national anaphylaxis data, 1992-2012. J Allergy Clin Immunol. 2015;135:956-963

18. Lin R.Y., Anderson A.S., Shah S.N., Nurruzzaman F. Increasing anaphylaxis hospitalizations in the first 2 decades of life: New York State, 1990-2006. Ann Allergy Asthma Immunol. 2008;101:387-393.

19. Jeppesen A.N., Christiansen C.F., Froslev T., Sorensen H.T. Hospitalization rates and prognosis of patients with anaphylactic shock in Denmark from 1995 through 2012. J Allergy Clin Immunol. 2016;137:1143-1147

20. Khasawneh FA, Slaton MA, Katzen SL, et al. The prevalence and reliability of self-reported penicillin allergy in a community hospital. Int J Gen Med. 2013;6:905-909. Published 2013 Dec 6. doi:10.2147/IJGM.S54559

21. L. Savic, L. Gurr, V. Kaura, J. Toolan, J.A.T. Sandoe, P.M. Hopkins, S. Savic. Penicillin allergy delabelling ahead of elective surgery: feasibility and barriers. British Journal of Anaesthesia. 2019;123(1):110-116

22. Marwood, J., Aguirrebarrena, G., Kerr, S., Welch, S.A. and Rimmer, J. (2017), De-labelling self-reported penicillin allergy within the emergency department through the use of skin tests and oral drug provocation testing. Emergency Medicine Australasia, 29: 509-515. doi:10.1111/1742-6723.12774

23. International Collaborative Study of Severe Anaphylaxis. Risk of anaphylaxis in a hospital population in relation to the use of various drugs: an international study. Pharmacoepidemiol Drug Saf. 2003;12:195-202.

24. Macy E, Contreras R. Adverse reactions associated with oral and parenteral use of cephalosporins: a retrospective population-based analysis. J Allergy Clin Immunol. 2015;135:745-752.

25. Yang, M-S, Kang, D-Y, Seo, B, et al. Incidence of cephalosporin-induced anaphylaxis and clinical efficacy of screening intradermal tests with cephalosporins: A large multicenter retrospective cohort study. Allergy. 2018; 73: 1833- 1841. https://doi.org/10.1111/all.13435

26. Klein NC, Cunha BA. Third-generation cephalosporins. Med Clin North Am. 1995 Jul;79(4):705-19.

27. Rodrigues J, Cruz LG, Botelho C, Rio E, Castel-Branco MG. Successful desensitisation to ceftriaxone in a patient with doxycicline resistant Lyme disease [published correction appears in Allergol Immunopathol (Madr). 2009 Jul-Aug;37(4):222]. Allergol Immunopathol (Madr). 2009;37(2):105106. doi:10.1016/s0301-0546(09)71113-9

28. Wazny LD, Daghigh B. Desensitization protocols for vancomycin hypersensitivity, Ann Pharmacother, 2001, vol. 35 (pg. 1458-64) 
29. Metz GM, Thyagarajan A. A successful protocol for daptomycin desensitization, Ann Allergy Asthma Immunol, 2008, vol. 100 pg. 87

\section{Figures}

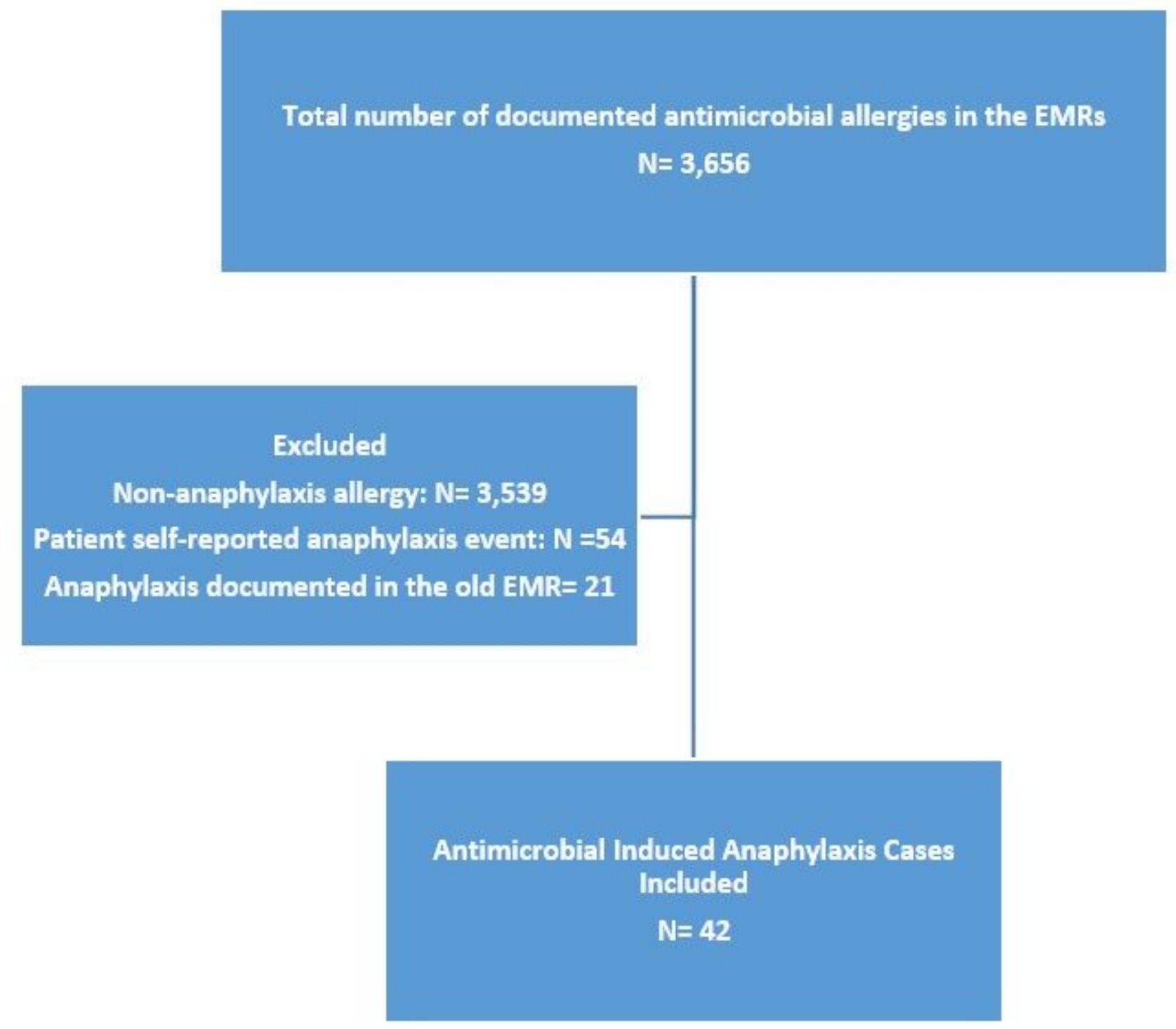

\section{Figure 1}

Patient Selection. Abbreviations: EMR: Electronic Medical Record 
(a)

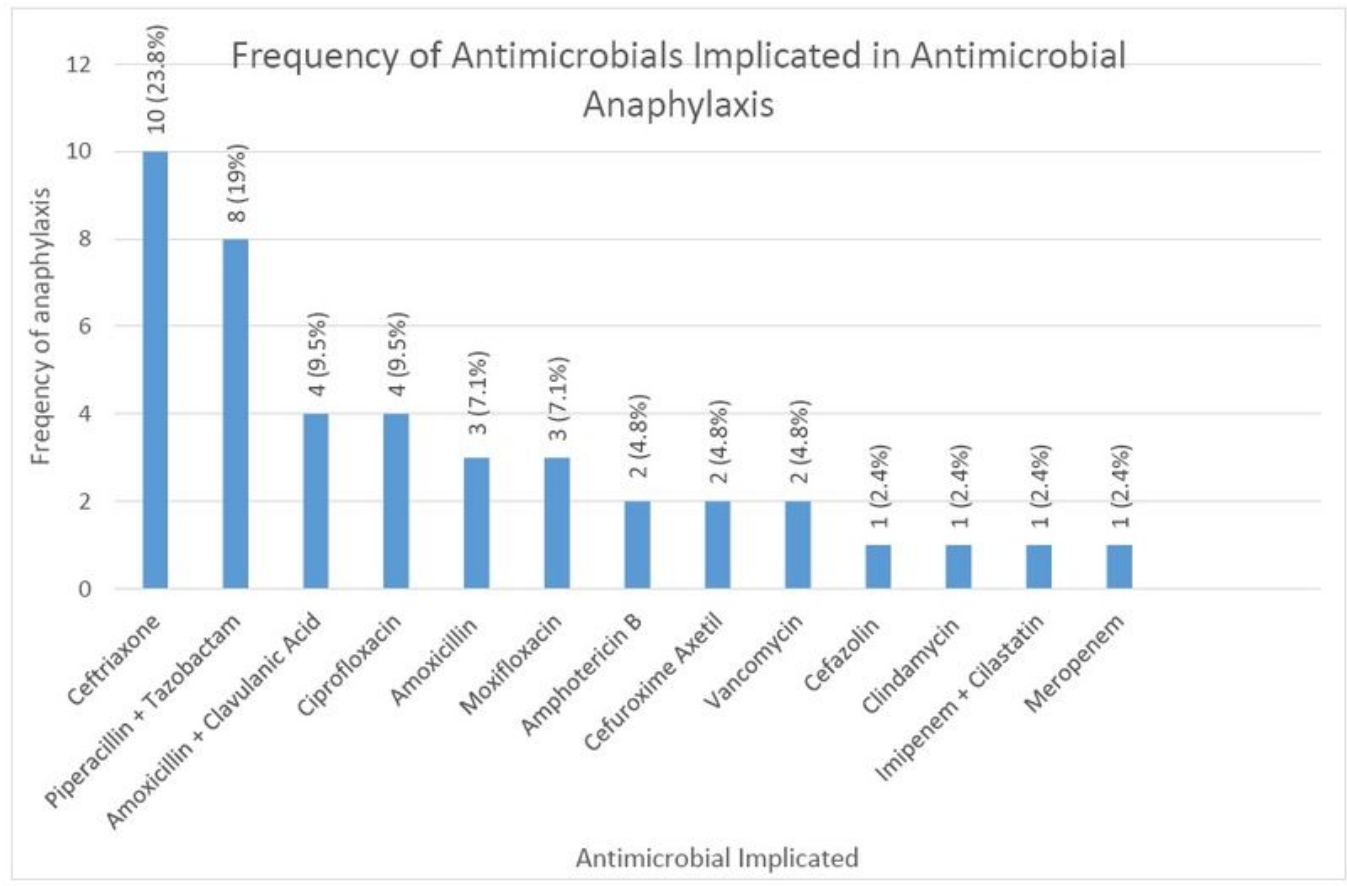

(b)

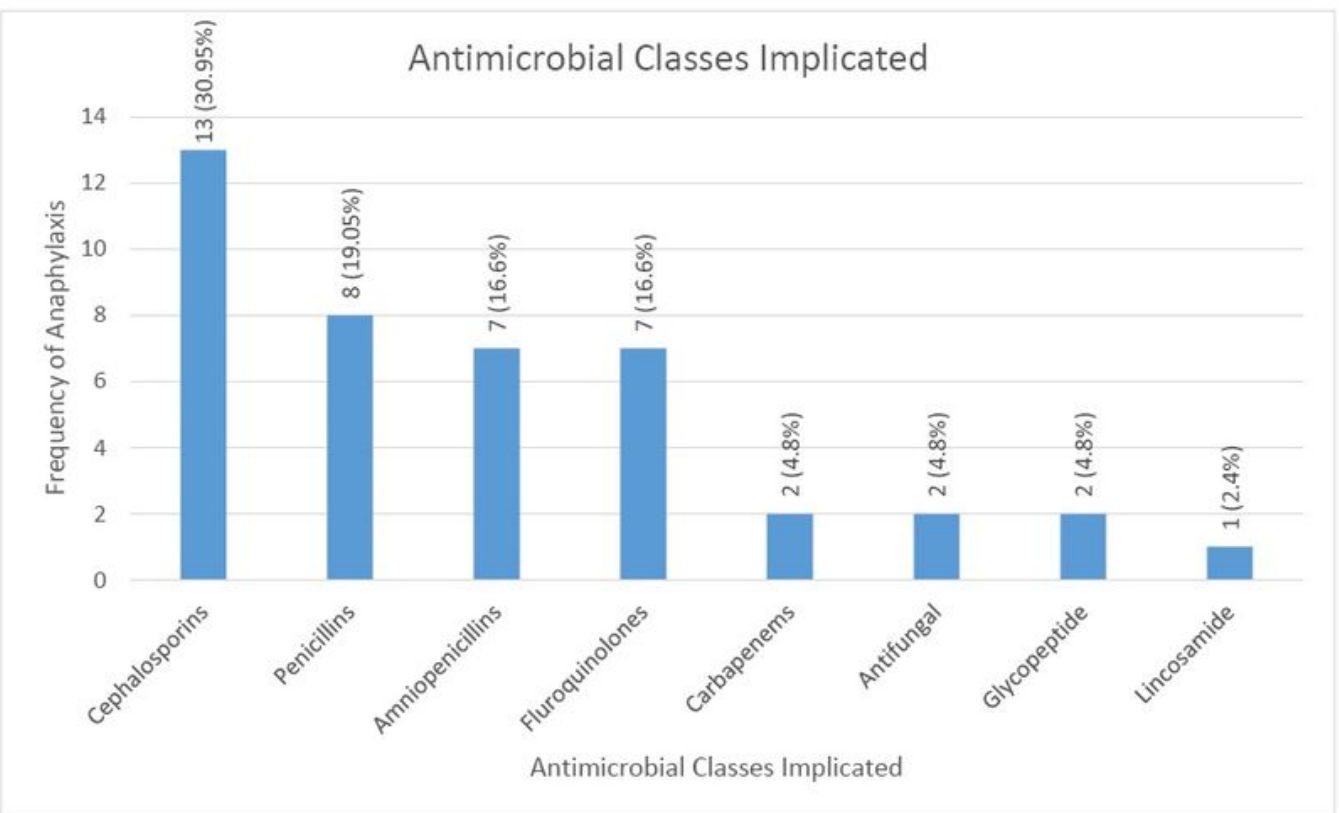

Figure 2

(a) Anaphylaxis episodes per implicated individual antimicrobial. All implicated antimicrobials $(\mathrm{N}=42)$. (b) Anaphylaxis episodes per antimicrobial class. 